\title{
Pathogen-host interaction mediated by vesicle-based secretion in schistosomes
}

\author{
Miriam Bischofsberger $^{1} \cdot$ Franziska Winkelmann $^{1} \cdot$ Anne Rabes $^{1} \cdot$ Emil C. Reisinger ${ }^{1} \cdot$ Martina Sombetzki $^{1}$ (D)
}

Received: 27 January 2020 / Accepted: 15 May 2020 / Published online: 27 May 2020

(C) The Author(s) 2020

\begin{abstract}
As part of the parasite's excretory/secretory system, extracellular vesicles (EVs) represent a potent communication tool of schistosomes with their human host to strike the balance between their own survival in a hostile immunological environment and a minimal damage to the host tissue. Their cargo consists of functional proteins, lipids, and nucleic acids that facilitate biological processes like migration, nutrient acquisition, or reproduction. The most important impact of the vesicle-mediated communication, however, is the promotion of the parasite survival via mimicking host protein function and directly or indirectly modulating the immune response of the host. Overcoming this shield of immunological adaption in the schistosome-host relation is the aim of current research activities in this field and crucial for the development of a reliable anti-schistosomal therapy. Not least because of their prospective use in clinical applications, research on EVs is now a rapidly expanding field. We herein focus on the current state of knowledge of vesicle-based communication of schistosomes and discussing the role of EVs in facilitating biological processes and immune modulatory properties of EVs considering the different life stages of the parasite.
\end{abstract}

Keywords Schistosoma mansoni $\cdot$ Extracellular vesicles $\cdot$ EV based communication $\cdot$ Parasite host interaction

\section{Introduction}

Billions of people worldwide are hosts of parasites, which contribute to a large extent to the global health burden of infectious origin (Torgerson et al. 2015). It is believed that hundreds of helminth species and protozoa can affect humans. Only a small portion of these pathogens are responsible for the world's most important and debilitating parasitic diseases, e.g., malaria, Chagas' disease, and schistosomiasis (Montaner et al. 2014). Critical for all internal parasites, regardless of the kingdom they belong to, is their obligatory host dependence for survival and reproduction. They often undergo multiple life cycle transformations with asexual and sexual replication phases in several hosts (Mantel and Marti 2014). This survival mode requires not only an enormous ability to

Handling Editor: Klaudia Brix

Martina Sombetzki

martina.sombetzki@uni-rostock.de

1 Department of Tropical Medicine, Infectious Diseases and Section of Nephrology, University Medical Center Rostock, Rostock, Germany adapt to different environmental conditions but also a high resistance to the various defense mechanisms of the hosts. To hijack their host organisms and make them useful for their specific needs, worms have developed into master manipulators of the immune system during co-evolutionary development with their specific hosts. For this purpose, parasites use extracellular vesicles (EV) as an effective tool for inter-cellular, inter-tissue, and cross-organism communication. Formally considered as garbage-bins, EVs are today recognized as extended arm of the parasite for balancing their own survival and the host pathology. The cargo of EVs consists of functional proteins, lipids, nucleic acids used to regulate tissue repair, neural communication, transfer of pathogenic proteins, and regulation of immune responses (Marcilla et al. 2012; Zhang et al. 2013). EVs appear as exosomes, microvesicles, apoptotic bodies, and other cell-derived membrane-enclosed vesicles (Fig. 2). Exosomes are synthesized through reverse budding of the late endosomal membrane. This results in the formation of multivesicular bodies (MVB) (Gustafson et al. 2017; Rodriguez-Boulan et al. 2005). Via fusion of MVBs with the outer membrane, exosomes are released into the extracellular environment (Piper and Katzmann 2007; Li et al. 2015). Subsequently they exert their biological function via (i) 
binding of target cells mediated by specific ligand-receptor recognition and triggering downstream signaling, or (ii) by directly delivering cargo due to rapid fusion with the target cell membrane (van Dongen et al. 2016). This is a very basic description of the numerous types of vesicles. Not least due to the absence of appropriate isolation techniques of these heterogeneous membranebound carriers, questions regarding the molecular mechanisms behind intercellular communication, tagging and merging with target cells, specific delivering of cargo, etc. cannot be answered in detail so far. It is obvious that the communication between parasite and host is not only unidirectional. Almost every cell can produce and release EV under healthy (Raposo and Stoorvogel 2013) and pathological conditions (Hristov et al. 2004). In the context of a parasitic infection, host-derived EVs efficiently activate immune responses. It has been shown that plasma cell-derived vesicles induce CD40 on antigen-presenting cells in response to an infection with Plasmodium berghei and therefore driving potential $\mathrm{T}$ cell priming and effector initiation for subsequent parasite eradication (Couper et al. 2010). In other studies, it has been shown that Leishmania major or Toxoplasma gondii pulsed dendritic cells form exosomes that induce protective Th1 immunity against these parasites (Aline et al. 2004; Coakley et al. 2016).

Schistosomiasis, caused by blood flukes (trematode worms) of the genus Schistosoma spp., is considered the most important helminthic disease in terms of morbidity and mortality, with more than 240 million infected people worldwide (Andrade 2009). The parasites invade humans and other mammalian hosts via skin and migrate through the lungs to the mesenteric blood vessels where they reach maturity as adult worms (Gryseels et al. 2006). Disease symptoms include spleno- and hepatomegaly, periportal fibrosis, portal hypertension (S. mansoni), urinary obstruction, bladder carcinoma (S. haematobium), and sterility. By virtue of serious health and social consequences for the chronically affected people and the growing concerns over resistance, there is continued pressure to identify and validate new schistosome drug targets and vaccine candidates (Fonseca et al. 2015). Characteristic of infection with schistosomes, and helminths in general, are the longevity of the parasites within the mammalian host, repeated re-infections due to less or no induction of immunity, and selective immune suppression to prevent protective Th2 responses (Taylor et al. 2012). As other helminths, schistosomes employ EVs to enable migration through the body, maturation, and immune evasion. Every life-stage of schistosomes has developed its own ingenious skills to communicate with the host via EVs for the maintenance of biological functions, and the creation of a "parasite-friendly" environment (Fig. 1).

\section{Cercariae to skin stage}

Aquatic cercariae represent the infectious life stage of the parasite. The main challenge of cercariae consists in the invasion of the mammalian host skin and dealing with innate immune defense mechanisms of the host. They are considered as complement sensitive in contrast to later larvae stages (Braschi et al. 2006). Cercariae are $500 \mu \mathrm{m}$ long and consist of an anterior region (oral sucker), the body segment and the typical bifurcated tail. S. mansoni cercariae have two pairs of preacetabular and three pairs of postacetabular glands. Since there is no de novo synthesis of proteins by cercariae, gland contents have to be pre-formed in earlier parasite life stages (Harrop and Wilson 1993). Right after the attachment to the skin, cercariae start transformation into schistosomula or "skin-stage." Therefore, it is difficult to classify the source of the vesicles secreted (Fig. 2).

Acetabular glands are a source of several serine proteases with elastase activity, which among others, are capable to degrade macromolecules in the skin. Proteases of S. mansoni cercariae are either packed in EVs or are secreted as soluble ES products. They form small tissue gaps within the skin and surround the cercariae like a protective wall or "smoke screen" (Mountford and Trottein 2004; Jenkins et al. 2005; Curwen et al. 2006). The most abundant proteases found in glandular secretions of $S$. mansoni are cercarial elastase (SmCE). However, S. japonicum cercariae are distinguishable from cercariae of other Schistosoma species in regard to the success (lower host specificity) and speed of migration through the skin (Ruppel et al. 2004). It is assumed that in regard to $S$. japonicum, other classes of proteases are involved in host invasion (Ingram et al. 2012). SmPepM8, a metalloprotease of the leishmanolysin family, was found to be another abundant constituent of $S$. mansoni cercarial secretions. In leishmaniosis leishmanolysin enhances skin passage of the parasite. A similar function for the $S$. mansoni version of this protein can be expected. The same applies to another secreted cercarial protease, SmDPP IV. SmDPP IV is known to be involved in skin invasion processes in other organisms, which implies a similar function in S. mansoni infection (Curwen et al. 2006; Silva et al. 2012). A chymotrypsin-like serine protease (SmCE), secreted by glands, is capable to cleave a variety of human skin macromolecules, including insoluble elastin (Salter et al. 2000). The function of a $28-\mathrm{kDa}$ glutathione-S-transferase (Sm28GST) is associated with detoxification processes of parasite and host derived products and is involved in controlling parasite fertility. Together with Sm28GST, S. bovis 28-GST and other molecules, like Sb14-3-3, are currently being intensively studied as potential vaccine candidates (Hansell et al. 2008; Riveau et al. 2018; de la Torre-Escudero et al. 2016).

Most of the excretory/secretory (E/S) products of transforming S. mansoni cercariae are proteins with immunomodulatory potential (Jenkins et al. 2005). Fluorescence labelling of E/S products (proteases or esterases) of transforming $S$. mansoni cercariae resulted in clearly visible vesicles released by cercarial acetabular glands. Macrophages and dendritic cells are able to incorporate the labeled E/S 
Fig. 1 Biogenesis of extracellular vesicles. Broadly categorized, there are three types of vesicles: (A) Microvesicles are originated by outward budding and fusion of the plasma membrane; (B) exosomes arise from fusion of multivesicular bodies (MVB) with the plasma membrane. MVB derive from developing early to late endosomes. Inward budding of endosomal membrane forms intraluminal vesicle that are released upon fusion with the plasma membrane, $(\mathbf{C})$ apoptotic blebs are released by cells undergoing apoptosis (modified from Gustafson et al. 2017)

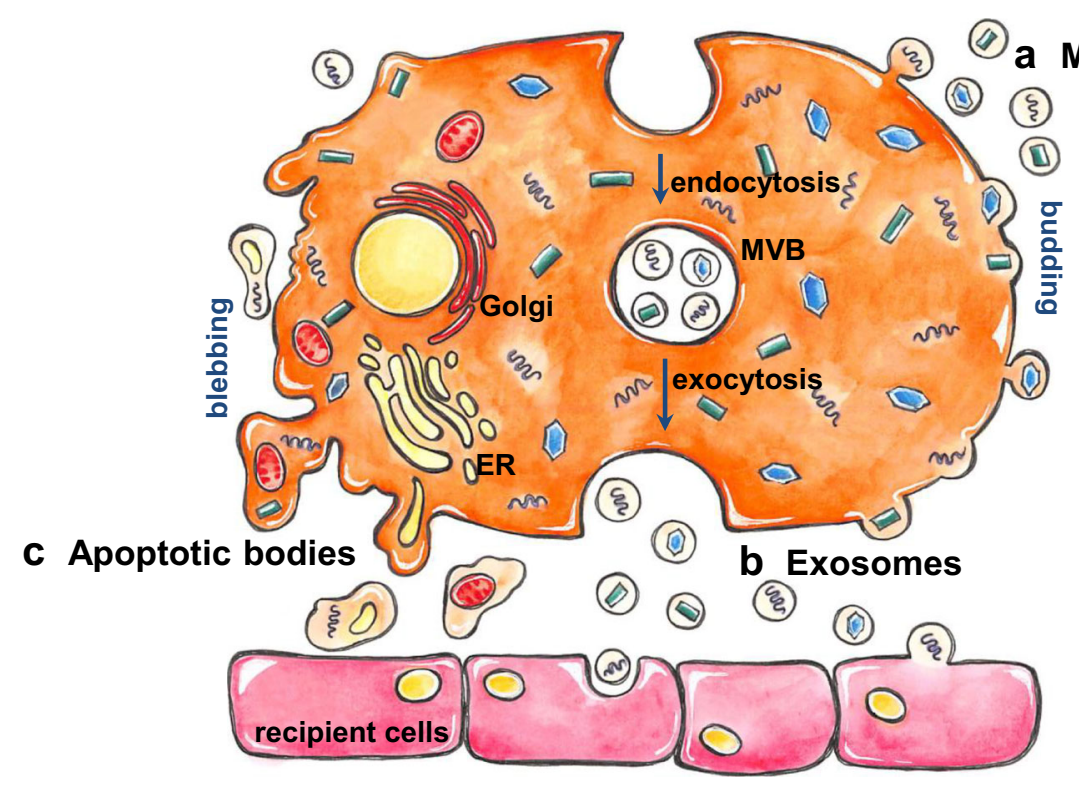

material via an active actin and $\mathrm{Ca} 2+-$ dependent phagocytic process. In vitro and in vivo, this mechanism has shown to trigger the development of Th2 polarizing dendritic cells (Paveley et al. 2009). Glycomic analysis of E/S products of transforming cercariae and eggs revealed the Lewis X (Lex) as one major terminal structure. Lex is a strong inducer of immune modulators like interkeukin-10 and prostaglandin (E2) (Jang-Lee et al. 2007). Lex-containing glycoconjugates drive maturation of native dendritic cells (DC) to a DC type 2 phenotype in a toll-like receptor 4-dependent manner, consequently leading to Th2-type responses (Curwen et al. 2006; Silva et al. 2012). Proteomic analysis of S. mansoni acetabular gland vesicles identified different cercarial elastase species, as well as paramyosin and SPO-1 (Sm16) (Knudsen et al. 2005). Paramyosin is a well-known inhibitor of the complement membrane attacking complex (MAC) and the classical complement activation pathway by $\mathrm{C} 1 \mathrm{q}$ binding (Deng et al. 2003). Paramyosin binding of complement factors $C 8$ and C9 leads to blockage of MAC formation and finally cell lysis. Anti-inflammatory SPO-1 or SmSPO-1, known to be expressed in sporocysts (an earlier snail stage of schistosomes), is a major protein secreted via EVs in cercariae and schistosomula (Rao and Ramaswamy 2000). In vitro, SPO-1 downregulates interleukin $1 \alpha$ expression in human keratinocytes, prevents lymphoproliferation, and suppresses intercellular adhesion molecule-1 (ICAM-1) expression in
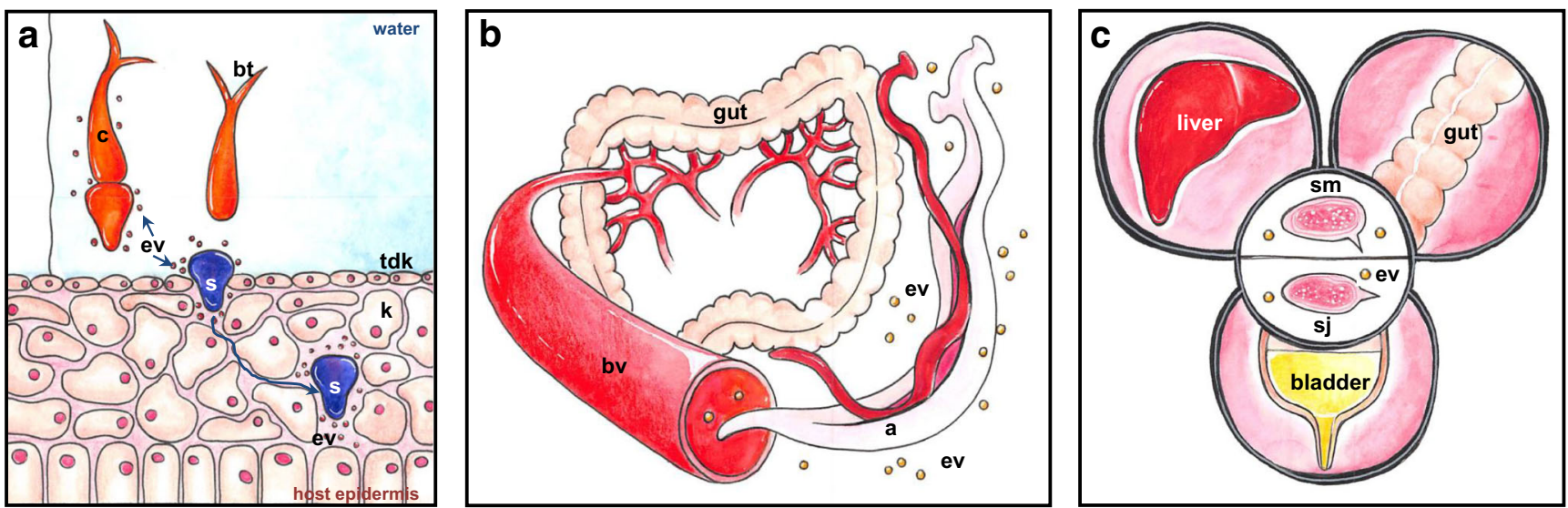

Fig. 2 Life stages of schistosomes affecting the host via vesicle-based communication. (A) Aquatic cercaria (c) is attracted to the human skin (tdk, terminally differentiated keratinocytes) by chemotrophic host signaling. During skin invasion the bifurcated tail (bt) is detached to initiate formation of the schistosomulum (s). Extracellular vesicles (ev) contain molecules, which support penetration of the membrane, and migration of the newly transformed schistosomulum (modified from Egesa et al. 2018). (B) Intravascular adult worms (a) secrete extracellular vesicles to coordinate migration within blood vessels (bv), nutrient acquisition, maintenance of hemostasis, and egg production. (C) miRNA containing extracellular vesicles (ev) from parasite eggs (sm, S. mansoni; sj, S. japonicum) can transfer their cargo to recipient cells. Apart of facilitating life stage-specific functions, all schistosome life stages use the vesicular signaling to modulate the host immune system in favor of their own survival 
endothelial cells (Ramaswamy et al. 1997). Following invasion of the skin, cercariae shed their immunogenic outer membrane, the glycocalyx, which initiates transformation of cercariae into the next larvae stage, i.e., the schistosomulum. This process is mediated by a $26-\mathrm{kDa}$ serine protease found in secreted exosome-like vesicles. Here it is important to mention that cercarial EVs itself activate MAC to lyse vesicles and release vesicle contents to the environment (Da'dara and Krautz-Peterson 2014). MAC initiates the rupture of vesicles along the cercarial surface, facilitating release of vesicle contents and thus enables shedding of the glycocalyx and migration through the skin layers. This clearly demonstrates of how cercariae use a part of the host's innate immune defense system to their own advantage.

\section{Schistosomula}

The most abundant molecules found in E/S products of schistosomula are involved in stress response, carbohydrate metabolism, and protein degradation (Cao et al. 2016a, b). This reflects the challenges they have to face within the human body which are the following: adaption from an aerobic to an anaerobic metabolism, defending host immune responses, migration through the skin, and changing of their body structure.

Schistosomal EVs are originated from unicellular acetabular or head glands (Nowacki et al. 2015b). Proteome analysis of exosome-like vesicle contents of $S$. mansoni schistosomula revealed tetraspanins, heat shock proteins (HSP), annexins, Rab 11 proteins, 14-3-3 protein isoforms, cytoskeletal proteins, and metabolic enzymes. For not all of the proteins found in vesicles a function has been defined yet. Due to their abundance in other organisms, however, functions can often be deducted (Table 1). Glycerinaldehyde-3-phosphate (GAPDH), present in S. mansoni schistosomal EVs (Nowacki et al. 2015b), binds to plasminogen and thus facilitates the invasion and migration of schistosomes.

\section{Adult schistosomes}

An EV-based interaction between adult parasite and host was first described for S. mansoni in 1961 (Kuipers et al. 2018; Senft et al. 2006). They release cup-shaped exosome-like vesicles ranging from 50 to $130 \mathrm{~nm}$ size enriched in nucleic acid, proteins, cholesterol, and lipids (Samoil et al. 2018; Sotillo et al. 2016a). Exosome-like vesicles isolated from adult $S$. japonicum were found to have a typical spherical shape and a diverse population that varies in size of 30-100 nm (Wang et al. 2015). In this article we focus exclusively on molecules that have been identified as vesicles constitutes.

Lipids are critical components of exosomes and small extracellular vesicles. They build up a protective lipid bilayer that is directly exposed to the environment and represents the interacting surface with recipient host cells. The cargo of exosomes contains a variety of lipid types, including phosphatidylserine, sphingomyelin, cholesterol, and plasmalogen. Phospholipid lysophosphatidylcholine (LPC) increases the surface tension of the membrane and therefore influences exosome stability and function in vivo (Munder et al. 1979). LPC and prostaglandin (PG) D2, derived from S. mansoni, activate eosinophils via toll-like receptor 2 (TLR2), and prostaglandin D2 receptor 1 (DP1) fosters the release of TGF- $\beta$ to support both fibrosis and tissue repair (Cao et al. 2016a, b; Nowacki et al. 2015a). The tegumental version of TLR 2 promotes maturation of dendritic cells which in turn induce regulatory $\mathrm{T}$ cell development (van der Kleij et al. 2002).

Various proteome analyses have been conducted on E/S products of adult schistosomes. In contrast to mammals or bacteria, only a limited number of schistosomal E/S proteins contain signal peptides and are referred to as atypical or nonsecretory, like HSPs, enolase, GAPDH, GST, 14-3-3 proteins, and a fatty acid binding protein (Liao et al. 2011). All these proteins have already been purified from schistosome vesicles and described as the most frequently secreted proteins in S. japonicum and S. mansoni (Samoil et al. 2018). Vesicle proteins of adult schistosomes include well-described exosomal markers designated in ExoCarta (Simpson et al. 2012), e.g., HSP70, energy-generating enzymes (e.g., enolase, pyruvate kinase, GAPDH, phosphoglycerate kinase 1), cytoskeletal proteins (actin, tubulin, fimbrin), tetraspanins (TSPs; e. g., TSP-1, TSP-4, TSP-18), and others (Knudsen et al. 2005; Deng et al. 2003). Proteomic analysis and classification by gene ontology (GO) annotation of vesicle contents of adult $S$. mansoni revealed a high incidence of proteins with catalytic and/or binding activity and proteins involved in metabolic and cellular processes. There is a great diversity of exosomal proteins but little is known about their function. S. japonicum exosomal enzymes induces classic activation of macrophages (M1), which produce pro-inflammatory mediators like TNF- $\alpha$, CD 16/32, and inducible nitric oxide synthase (iNOS) (Wang et al. 2015).

Extracellular vesicle-enclosed microRNAs (miRNAs) of adult $S$. mansoni and $S$. japonicum were shown to play an essential role in modulating host immune responses (Samoil et al. 2018; Zhang et al. 2017; Cheng et al. 2013; Hoy et al. 2014) and act as important mediators of cell communication (Turchinovich et al. 2013; Hu et al. 2012). MicroRNAs (miRNAs) are short, highly conserved, non-coding RNA molecules that occur naturally in the genomes of plants and animals. The 17 to 27 long nucleotides target specific mRNAs and therefore regulate posttranscriptional mRNA expression. This results in translation suppression and gene silencing. At present, 79 mature miRNAs in S. japonicum and 225 mature miRNAs in $S$. mansoni have been documented in miRBase 
Table 1 Assumed functions of proteins found in different Schistosoma species and life stages

\begin{tabular}{|c|c|c|c|}
\hline Protein & Species & Described function & Ref. \\
\hline \multicolumn{4}{|l|}{ Cercariae } \\
\hline Paramyosin & S. mansoni & Immunogenic, inhibitor of the complement system & (Knudsen et al. 2005) \\
\hline SPO-1 (Sm16) & S. mansoni & $\begin{array}{l}\text { Anti-inflammatory, downregulates IL1- } \alpha \text { in keratinocytes, prevents } \\
\text { lymphoproliferation, suppresses ICAM-1 on endothelial cells }\end{array}$ & (Knudsen et al. 2005) \\
\hline FBA & S. mansoni & Granuloma downregulation & (Marques et al. 2008) \\
\hline $\begin{array}{l}\text { Myosin heavy } \\
\text { chain }\end{array}$ & S. mansoni & Potent stimulator of IFN- $\gamma$ of $\mathrm{CD}^{+}$cells & (Eberl et al. 2000) \\
\hline PEPCK & S. mansoni & Induce a balanced $\mathrm{Th} 1 / \mathrm{Th} 2$ response & (Rutitzky et al. 2001) \\
\hline GAPDH & $\begin{array}{l}\text { S. japonicum, } S \text {. } \\
\text { mansoni }\end{array}$ & $\begin{array}{l}\text { Inhibitor of the complement system (binding of plasminogen and } \\
\text { complement factor } \mathrm{C} 3 \text { ) }\end{array}$ & (Cao et al. 2016a, 2016b) \\
\hline Calcium ATPase & S. mansoni & Control of calcium homeostasis & (Noël et al. 2001) \\
\hline Tropomyosin & S. mansoni & Cytoskeletal protein & (MacGregor and Shore 1990) \\
\hline TPI & $\begin{array}{l}\text { S. japonicum, } \\
\text { S. mansoni }\end{array}$ & $\begin{array}{l}\text { Converts glyceraldehyde-3-phosphate to dehydroxyacetone phosphate, } \\
\text { a key reaction in glycolysis }\end{array}$ & $\begin{array}{l}\text { (Sun et al. 1999) (dos Reis et al. } \\
\text { 1993) }\end{array}$ \\
\hline GST & S. mansoni & $\begin{array}{l}\text { Associated with detoxification processes of parasite, involved in controlling } \\
\text { parasite fertility }\end{array}$ & (Hansell et al. 2008) \\
\hline $\mathrm{CE}$ & S. mansoni & Cleaves skin macromolecules e.g. insoluble elastin & $\begin{array}{l}\text { (Salter et al. 2000; Ingram et al. } \\
\text { 2011) }\end{array}$ \\
\hline Calpain & S. mansoni & Cytoskeletal remodeling & (Fox et al. 1990) \\
\hline \multicolumn{4}{|l|}{ Schistosomula } \\
\hline Rab11 & $\begin{array}{l}\text { S. mansoni, } \\
\text { S. japonicum }\end{array}$ & Fusion of multi-vesicular bodies (MVB) with the plasma membrane & (Beckett et al. 2013) \\
\hline CD63 antigen & $\begin{array}{l}\text { S. mansoni, } \\
\text { S. japonicum }\end{array}$ & Formation/cargo sorting of intraluminal vesicles in MVBs & (Baietti et al. 2012) \\
\hline Syntaxin & S. mansoni & Q-SNARE, mediate vesicle-fusion & (Koles et al. 2012) \\
\hline Calpain & S. mansoni & Cytoskeletal remodeling & (Fox et al. 1990) \\
\hline \multicolumn{4}{|l|}{ Adult worms } \\
\hline TSP-2 & S. japonicum & $\begin{array}{l}\text { Member of tetraspanins, linked to the immune evasion of schistosomes and } \\
\text { tegument turnover, structural organization of the tegument }\end{array}$ & (Tran et al. 2010; Cai et al. 2008) \\
\hline VAMP2 & S. japonicum & $\begin{array}{l}\text { Member of SNAREs, linked to membrane fusion, maintenance of tegument, } \\
\text { glucose uptake, worm development and egg production }\end{array}$ & (Han et al. 2017) \\
\hline VIP36 & S. mansoni & $\begin{array}{l}\text { L-type lectin, might participate in the complex secretory activity within the egg } \\
\text { envelope and tegument protein }\end{array}$ & (Ornelas et al. 2017) \\
\hline Calpain & S. mansoni & extracellular calpain activity, cleaving fibronectin & (Wang et al. 2017) \\
\hline ATPDase-1 & S. mansoni & $\begin{array}{l}\text { Hydrolyzes extracellular prothrombotic ATP and ADP, inhibiting platelet } \\
\text { aggregation and activation }\end{array}$ & (Da'Dara and Skelly 2014) \\
\hline Enolase & S. mansoni & Binds plasminogen and promote its activation & (Figueiredo et al. 2015a, 2015b) \\
\hline Sm22.6 & S. mansoni & Inhibition of human thrombin & (Lin and $\mathrm{He} 2006$ ) \\
\hline SP2 & S. mansoni & Trypsin-like protease, activates plasminogen \& bradykinine & (Leontovyč et al. 2018) \\
\hline POP & S. mansoni & Member of serine peptidase family S9, cleavage of bradykinin and angiotensin I & (Fajtová et al. 2015) \\
\hline CB1 & S. mansoni & $\begin{array}{l}\text { Degradation of TLR3 on macrophages, gut-associated peptidase, digestion } \\
\text { of human blood cells }\end{array}$ & $\begin{array}{l}\text { (Donnelly et al. 2010b) } \\
\text { (Jílková et al. 2014) }\end{array}$ \\
\hline $\begin{array}{l}\text { GAPDH } \\
\text { FBA }\end{array}$ & S. japonicum & Induce short-lived antibody responses & (Wang et al. 2017) \\
\hline GST & S. mansoni & Stimulate anti-fecundity immunity & (Riveau et al. 1998) \\
\hline HSP70 & S. mansoni & Elicits an early and strong antibody response in baboons & (Kanamura et al. 2002) \\
\hline Syntenin & S. mansoni & $\begin{array}{l}\text { Vaccination of mice with recombinant syntenin confers partial protection } \\
\text { against } S \text {. mansoni challenge infection and ameliorates parasite-induced liver } \\
\text { pathology }\end{array}$ & (Figueiredo et al. 2014) \\
\hline $\operatorname{Sm} 29$ & S. mansoni & $\begin{array}{l}\text { Activation of monocyte derived dendritic cells and lymphocytes in patients with } \\
\text { leishmaniasis }\end{array}$ & (Lopes et al. 2019) \\
\hline
\end{tabular}

ATPase, adenosine triphosphatase; ATPDase, ATP diphosphohydrolase; CB1, cathepsin B-like endopeptidase 1; CE, cercarial elastase; FBA, fructosebisphosphate aldolase; GAPDH, glyceraldehyde-3-phosphate dehydrogenase; GST, glutathione S-transferase; HSP70, heat shock protein $70 \mathrm{kDa}$; PEPCK, phosphoenolpyruvate carboxykinase; POP, prolyl oligopeptidase; Rab11, Rab-protein 11; Sj, Schistosoma japonicum; Sm, Schistosoma mansoni; Sm16, Schistosoma mansoni 16 kDa tegumental antigen; Sm22.6, Schistosoma mansoni $22.6 \mathrm{kDa}$ tegumental antigen; Sm29, Schistosoma mansoni $29 \mathrm{kDa}$ tegumental antigen; SNARE, Noluble N-ethylmaleimide-sensitive factor-attachment protein (SNAP) receptor; SPO-1 (Sm16), stagespecific protein-1; SP2, serine protease 2; TPI, triosephosphate isomerase; TSP-2, tetraspanin-2; VAMP2, vesicle-associated membrane protein 2; VIP36, vesicular integral membrane protein $36 \mathrm{kDa}$ 
(Version 21) (Zhu et al. 2016). For S. haematobium 89 transcribed miRNAs were identified in total including 34 novel species specific, with no homologs in other schistosomes (Stroehlein et al. 2018). Research on the biological significance of exosomal microRNA is still in its beginnings. Computer-based searches for potential human target regions have revealed conserved seed regions in schistosomal miRNAs of $S$. mansoni. Sma-bantam and sma-miR-36-3P were found to be enriched in vesicles of adult $S$. mansoni. Sma-miR125b, one of the most abundant miRNAs found in $S$. mansoni EVs, has been shown to have more than 600 potential human targets. For sma-bantam 39 potential human targets have been identified (Samoil et al. 2018). Bantam is an invertebrate-specific miRNA that was previously detected in serum samples of helminth-infected hosts and was reported to be secreted by the parasite (Cheng et al. 2013; Hu et al. 2012; Britton et al. 2014). It has been shown that vesicular miR-125b and bantam-mirRNA from $S$. japonicum are taken up by macrophages and other peripheral host blood immune cells. Incorporated miR-125b and bantam increases macrophage proliferation and TNF- $\alpha$ production by regulating corresponding targets including Pros1, Fam212b, and Clmp and thus contributes to parasite survival (Liu et al. 2019). An in vitro study of Meningher et al. (2020) has shown that adult schistosomes secrete miRNA-harboring extracellular vesicles that are internalized by Th cells (Meningher et al. 2020). They also found schistosomal miRNAs in T helper cells isolated from Peyer's patches and mesenteric lymph nodes of infected mice. As a target of MAP3K7, it has been shown that schistosomal miR-10 down-modulates NF- $\mathrm{BB}$ activity, a transcription factor for Th2 differentiation. Based on these results, the authors concluded that schistosomal miR-10 is involved in the downregulation of the Th2 response in the chronic course of the infection. Vesicle-packaged miRNAs were also tested as diagnostic tools and as a way to assess the severity of the disease. Meningher et al. (2017) could show that detection of two schistosomal miRNAs (bantam and miR-2c-3p) in sera of infected patients has comparable sensitivity (80\%-86\%) and the specificity (84\%-94\%) levels to commonly used serological tests (Meningher et al. 2017). In addition, the serum level of schistosomal miRNA has turned out to be a useful tool for the grading of hepatic fibrosis in Schistosomiasis (Cai et al. 2018). Four schistosomal miRNAs, miR-150-5p, let-7a-5p, let-7d-5p, and miR-146a-5p, have proven to be useful in this study to distinguish patients with mild versus severe fibrosis, with miR-150-5p as the most promising marker. In addition, all analyzed miRNAs have returned to normal levels in mice 6 months post-treatment.

Considering the localization of adult worms within the small mesenteric or pelvic veins, manipulation of vasodilatation and fibrinolysis represents an important adaption strategy of the parasite to the local environment. ATPdiphosphohydrolase 1 (ATPDase-1) is a membrane- associated protein that hydrolyzes extracellular prothrombotic ATP and ADP, thereby, inhibiting platelet aggregation and activation (Da'dara and Krautz-Peterson 2014; Kaczmarek et al. 1996; (Vasconcelos et al. 1996). Exosomal ATPDase-1 may represent an important mechanism of hemostatic control. Because of its plasminogen binding activity, the glycolytic enzyme enolase displays another exosomal protein with potential anti-clotting action (Gómez-Arreaza et al. 2014). The schistosomal antigen $\mathrm{Sm} 22.6$ is known to suppress the activity of host proteins like thrombin (Lin and He 2006), annexin (Madureira et al. 2011), and the calcium-dependent protease calpain. Vesicles containing parasite calpain alter calpain activity of the host and thus leading to impaired platelet aggregation (Kuchay and Chishti 2007).

Due to the production of eggs, female schistosomes ingest some 39.000 erythrocytes hourly (10 times more than male) (Figueiredo et al. 2015a, b), and digestion of blood constituents is largely extracellular (Skelly et al. 2014). The schistosomal esophagus is divided into an anterior and a posterior section. Each of these sections is surrounded by a dense assembly of glandular cell bodies displaying the origin of secretory vesicles. Once released into the intestinal lumen, they support digestion of blood (Li et al. 2014). Adult schistosomes habitually regurgitate their gut contents to expel the haemozoin. The vomitus contains a multitude of E/S proteins packed in exosome-like vesicles, e.g., hydrolytic enzymes required for the degradation of erythrocytes and host plasma constituents as well as carrier proteins promoting the uptake of lipids.

S. mansoni vesicles are also rich in proteases, including metallopeptidases, cysteine, and serine proteases that are believed to play important roles in exosome-mediated signaling (Shimoda and Khokha 2013). For example, novel serine proteases from family S1 trypsin-like named SmSP2 (Dvořák et al. 2016) and prolyl oligopeptidase from family S9 named SmPOP were shown to target bradykinin and angiotensin I (Fajtová et al. 2015). A homolog of leucine aminopeptidase (LAP), present in the adult worm gut, contributes to digestion of blood proteins (McCarthy et al. 2004). Some of these proteases and other tegumental proteins are promising vaccine candidates, including Sm-TSP-2 (Tran et al. 2006), Sm29 (Cardoso et al. 2006), and cytoplasmic dynein light chain (Rezende et al. 2011). Other proteases, e.g., cathepsin B-like peptidases, have immune regulatory activity. Macrophages of mice given a single injection of $S$. mansoni cathepsin B1 (SmCB1) differentiate into a Th2-associated M2 phenotype (Donnelly et al. 2010a). SmCB1 and other helminth cysteine peptidases act simultaneously as immunogens and adjuvants and are therefore interesting vaccine candidates (El Ridi et al. 2014). However, one of the major functions of this gutassociated peptidase is the digestion of human blood cells (Jílková et al. 2014). 
Another very interesting vesicle-derived vaccine candidate is GAPDH of $S$. japonicum. It was identified as a major antigen inducing a short-term antibody response (Wang et al. 2013). In different animal models, vaccination with GST of $28 \mathrm{kDa}$ resulted in a significantly reduced fecundity of female worms (Liu et al. 2009; Riveau et al. 1998). Authors found that GST is the most abundant $\mathrm{E} / \mathrm{S}$ protein of various parasites indicating highly conserved patterns of this protein. HSPs are also highly conserved and have been shown to be an immune stimulant such as SmHSP70 triggering an early humoral immune response and being a potential candidate for the use in immune diagnosis (Kanamura et al. 2002).

\section{Eggs}

Parasite eggs release bioactive E/S products, which are known to be powerful modulators of the host immune response (Dvoř́k et al. 2016; Knuhr et al. 2018). Different proteomic analyses of $S$. mansoni egg secretions revealed protein numbers from six (Mathieson and Wilson 2010) to 188 (Cass et al. 2007). In S. japonicum, 258 (Liu et al. 2006) or rather 957 egg-related proteins (De Marco Verissimo et al. 2019) were found. Due to a lack of information, it remains elusive to what extent $\mathrm{E} / \mathrm{S}$ products of eggs were secreted via vesicles. We found only one study that points to the release of miRNAcontaining EVs by $S$. japonicum eggs, which can transfer their cargo miRNAs to recipient cells in vitro (Zhu et al. 2016), while others doubt EV-mediated secretions by schistosome eggs (Sotillo et al. 2016b).

\section{Summary}

Vesicle contents of schistosomes facilitate life stage-specific requirements and biological processes like migration through the host body, feeding, or reproduction. However, the most important contribution of the vesicle-based communication is the promotion of parasite survival by modulating the immune response of the host (Han et al. 2009). By virtue of the strong immunological adaption of the host and the parasite, all attempts to develop a reliable anti-schistosomal vaccine have failed so far. Therefore, it is of crucial importance to understand and overcome the tightly regulated host-parasite "communication". As described above, a certain number of vesicular schistosomal molecules have already been assigned a function and some of them, in particular proteins, are considered to be promising vaccine candidates or diagnostic markers.

Acknowledgements Open Access funding provided by Projekt DEAL.
Funding information FW and MS were supported by the European Union (European Social Fund, Card-ii-Omics, ESF/14-BM-A55-0037/ 16, http://ec.europa.eu/esf/home.jsp). This work was supported by the European Social Fund (ESF_14-BM-A55-0036) within the excellence research program of the state Mecklenburg-Vorpommern Card-ii-Omics (to MS and FW). The author MS received a research grant from the DAMP foundation. The funders had no role in study design, data collection and analysis, decision to publish, or preparation of the manuscript.

\section{Compliance with ethical standards}

Conflict of interest The authors declare that there are no conflicts of interest regarding the publication of this paper.

Open Access This article is licensed under a Creative Commons Attribution 4.0 International License, which permits use, sharing, adaptation, distribution and reproduction in any medium or format, as long as you give appropriate credit to the original author(s) and the source, provide a link to the Creative Commons licence, and indicate if changes were made. The images or other third party material in this article are included in the article's Creative Commons licence, unless indicated otherwise in a credit line to the material. If material is not included in the article's Creative Commons licence and your intended use is not permitted by statutory regulation or exceeds the permitted use, you will need to obtain permission directly from the copyright holder. To view a copy of this licence, visit http://creativecommons.org/licenses/by/4.0/.

\section{References}

Aline F, Bout D, Amigorena S, Roingeard P, Dimier-Poisson I (2004) Toxoplasma gondii antigen-pulsed-dendritic cell-derived exosomes induce a protective immune response against $\mathrm{T}$. gondii infection. Infect Immun 72(7):4127-4137. https://doi.org/10.1128/IAI.72.7. 4127-4137.2004

Andrade ZA (2009) Schistosomiasis and liver fibrosis. Parasite Immunol 31(11):656-663. https://doi.org/10.1111/j.1365-3024.2009.01157.x

Baietti MF, Zhang Z, Mortier E, Melchior A, Degeest G, Geeraerts A, Ivarsson Y, Depoortere F, Coomans C, Vermeiren E, Zimmermann P, David G (2012) Syndecan-syntenin-ALIX regulates the biogenesis of exosomes. Nat Cell Biol 14:677-685. https://doi.org/10. $1038 / \mathrm{ncb} 2502$

Beckett K, Monier S, Palmer L, Alexandre C, Green H, Bonneil E, Raposo G, Thibault P, Borgne RL, Vincent JP (2013) Drosophila $\mathrm{S} 2$ cells secrete wingless on exosome-like vesicles but the wingless gradient forms independently of exosomes. Traffic. 14:82-96. https://doi.org/10.1111/tra.12016

Braschi S, Curwen RS, Ashton PD, Verjovski-Almeida S, Wilson A (2006) The tegument surface membranes of the human blood parasite Schistosoma mansoni: A proteomic analysis after differential extraction. Proteomics 6(5):1471-1482. https://doi.org/10.1002/ pmic. 200500368

Britton C, Winter AD, Gillan V, Devaney E (2014) MicroRNAs of parasitic helminths - identification, characterization and potential as drug targets. Int J Parasitol Drugs Drug Resist 4(2):85-94. https:// doi.org/10.1016/j.ijpddr.2014.03.001

Cai P, Bu L, Wang J, Wang Z, Zhong X, Wang H (2008) Molecular characterization of Schistosoma japonicum tegument protein tetraspanin-2: sequence variation and possible implications for immune evasion. Biochem Biophys Res Commun 372:197-202. https://doi.org/10.1016/j.bbrc.2008.05.042

Cai P, Mu Y, Olveda RM, Ross AG, Olveda DU, McManus DP (2018) Circulating miRNAs as footprints for liver fibrosis grading in 
schistosomiasis. EBioMedicine 37:334-343. https://doi.org/10. 1016/j.ebiom.2018.10.048

Cao X, Fu Z, Zhang M, Han Y, Han H, Han Q, Lu K, Hong Y, Lin J (2016a) ITRAQ-based comparative proteomic analysis of excretory-secretory proteins of schistosomula and adult worms of Schistosoma japonicum. J Proteome 138:30-39. https://doi.org/10. 1016/j.jprot.2016.02.015

Cao X, Fu Z, Zhang M, Han Y, Han Q, Lu K, Li H, Zhu C, Hong Y, Lin J (2016b) Excretory/secretory proteome of 14-day schistosomula, Schistosoma japonicum. J Proteome 130:221-230. https://doi.org/ 10.1016/j.jprot.2015.10.001

Cardoso FC, Pacífico RNA, Mortara RA, Oliveira SC (2006) Human antibody responses of patients living in endemic areas for schistosomiasis to the tegumental protein Sm29 identified through genomic studies. Clin Exp Immunol 144:382-391. https://doi.org/10.1111/j. 1365-2249.2006.03081.x

Cass CL, Johnson JR, Califf LL, Xu T, Hernandez HJ, Stadecker MJ, Yates JR III, Williams DL (2007) Proteomic analysis of Schistosoma mansoni egg secretions. Mol Biochem Parasitol 155: 84-93. https://doi.org/10.1016/j.molbiopara.2007.06.002

Cheng G, Luo R, Hu C, Cao J, Jin Y (2013) Deep sequencing-based identification of pathogen-specific microRNAs in the plasma of rabbits infected with Schistosoma japonicum. Parasitology 140(14): 1751-1761. https://doi.org/10.1017/S0031182013000917

Coakley G, Buck AH, Maizels RM (2016) Molecular \& Biochemical Parasitology Host parasite communications - messages from helminths for the immune system parasite communication and cell-cell interactions. Mol Biochem Parasitol 208(1):33-40. https://doi.org/ 10.1016/j.molbiopara.2016.06.003

Couper KN, Barnes T, Hafalla JCR, Combes V, Ryffel B, Secher T et al (2010) Parasite-derived plasma microparticles contribute significantly to malaria infection-induced inflammation through potent macrophage stimulation. PLoS Pathog 6(1):e1000744. https://doi. org/10.1371/journal.ppat.1000744

Curwen RS, Ashton PD, Sundaralingam S, Wilson RA (2006) Identification of novel proteases and immunomodulators in the secretions of Schistosome Cercariae that facilitate host entry. Mol Cell Proteomics 5:835-844. https://doi.org/10.1074/mcp.m500313mcp200

Da'dara AA, Krautz-Peterson G (2014) New insights into the reaction of Schistosoma mansoni cercaria to the human complement system. Parasitol Res 113(10):3685-3696. https://doi.org/10.1007/s00436014-4033-3

Da'Dara AA, Skelly PJ (2014) Schistosomes versus platelets. Thromb Res 134(6):1176-1181. https://doi.org/10.1016/j.thromres.2014.09. 032

de la Torre-Escudero E, Bennett APS, Clarke A, Brennan GP, Robinson MW (2016) Extracellular vesicle biogenesis in Helminths: more than one route to the surface? Trends Parasitol 32(12):921-929. https://doi.org/10.1016/j.pt.2016.09.001

De Marco Verissimo C, Potriquet J, You H, McManus DP, Mulvenna J, Jones MK (2019) Qualitative and quantitative proteomic analyses of Schistosoma japonicum eggs and egg-derived secretory-excretory proteins. Parasit Vectors 12(1):1-16. https://doi.org/10.1186/ s13071-019-3403-1

Deng J, Gold D, LoVerde PT, Fishelson Z (2003) Inhibition of the complement membrane attack complex by Schistosoma mansoni Paramyosin. Infect Immun 71(11):6402-6410. https://doi.org/10. 1128/iai.71.11.6402-6410.2003

Donnelly S, O’Neill SM, Stack CM, Robinson MW, Turnbull L, Whitchurch C, Dalton JP (2010a) Helminth cysteine proteases inhibit TRIF-dependent activation of macrophages via degradation of TLR3. J Biol Chem 285:3383-3392. https://doi.org/10.1074/jbc. M109.060368

Donnelly S, O'Neill SM, Stack CM, Robinson MW, Turnbull L, Whitchurch C, Dalton JP (2010b) Helminth cysteine proteases inhibit TRIF-dependent activation of macrophages via degradation of TLR3. J Biol Chem 285(5):3383-3392. https://doi.org/10.1074/ jbc.M109.060368

dos Reis MG, Davis RE, Singh H, Skelly PJ, Shoemaker CB (1993) Characterization of the Schistosoma mansoni gene encoding the glycolytic enzyme, triosephosphate isomerase. Mol Biochem Parasitol 59(2):235-242. https://doi.org/10.1016/0166-6851(93) 90221-I

Dvořák J, Fajtová P, Ulrychová L, Leontovyč A, Rojo-Arreola L, Suzuki $\mathrm{BM}$ et al (2016) Excretion/secretion products from Schistosoma mansoni adults, eggs and schistosomula have unique peptidase specificity profiles. Biochimie. 122:99-109. https://doi.org/10.1016/j. biochi.2015.09.025

Eberl M, Beck E, Coulson PS, Okamura H, Wilson RA, Mountford AP (2000) IL-18 potentiates the adjuvant properties of IL-12 in the induction of a strong Th1 type immune response against a recombinant antigen. Vaccine. 18:2002-2008. https://doi.org/10.1016/ S0264-410X(99)00532-0

Egesa M, Lubyayi L, Tukahebwa EM, Bagaya BS, Chalmers IW, Wilson S, Hokke CH, Hoffmann KF, Dunne DW, Yazdanbakhsh M, Labuda LA, Cose S (2018) Parasite Immunol 40(12):e12592

El Ridi R, Tallima H, Selim S, Donnelly S, Cotton S, Santana BG, Dalton JP (2014) Cysteine peptidases as schistosomiasis vaccines with inbuilt adjuvanticity. PLoS One 9:e85401. https://doi.org/10.1371/ journal.pone.0085401

Fajtová P, Štefanić S, Hradilek M, Dvořák J, Vondrášek J, Jílková A, Ulrychová L, McKerrow JH, Caffrey CR, Mareš M, Horn M (2015) Prolyl oligopeptidase from the blood fluke Schistosoma mansoni: from functional analysis to anti-schistosomal inhibitors. PLoS Negl Trop Dis 9. https://doi.org/10.1371/journal.pntd.0003827

Figueiredo BC, Assis NRG, Morais SB, Ricci ND, Pinheiro CS, Martins VP, Bicalho RM, da'dara AA, Skelly PJ, Oliveira SC (2014) Schistosome Syntenin partially protects vaccinated mice against Schistosoma mansoni infection. PLoS Negl Trop Dis 8:e3107. https://doi.org/10.1371/journal.pntd.0003107

Figueiredo BC, Da'dara AA, Oliveira SC, Skelly PJ (2015a) Schistosomes enhance plasminogen Activation: The Role of Tegumental Enolase. PLoS Pathog. https://doi.org/10.1371/ journal.ppat. 1005335

Figueiredo BCP, Ricci ND, de Assis NRG, de Morais SB, Fonseca CT, Oliveira SC (2015b) Kicking in the guts: Schistosoma mansoni digestive tract proteins are potential candidates for vaccine development. Front Immunol 6(JAN):1-7. https://doi.org/10.3389/fimmu. 2015.00022

Fonseca CT, Oliveira SC, Alves CC (2015) Eliminating schistosomes through vaccination: what are the best immune weapons? Front Immunol 6(MAR):1-8. https://doi.org/10.3389/fimmu.2015.00095

Fox JEB, Austin CD, Boyles JK, Steffen PK (1990) Role of the membrane skeleton in preventing the shedding of procoagulant-rich microvesicles from the platelet plasma membrane. J Cell Biol 111(2):483-493. https://doi.org/10.1083/jcb.111.2.483

Gómez-Arreaza A, Acosta H, Quiñones W, Concepción JL, Michels PAM, Avilán L (2014) Extracellular functions of glycolytic enzymes of parasites: unpredicted use of ancient proteins. Mol Biochem Parasitol 193:75-81. https://doi.org/10.1016/j. molbiopara.2014.02.005

Gryseels B, Polman K, Clerinx J, Kestens L (2006) Human schistosomiasis. Lancet 368(9541):1106-1118. https://doi.org/10.1016/S01406736(06)69440-3

Gustafson D, Veitch S, Fish JE (2017) Extracellular vesicles as protagonists of diabetic cardiovascular pathology. Front Cardiovascu Med 4(November):1-12. https://doi.org/10.3389/fcvm.2017.00071

Han Q, Jia B, Hong Y, Cao X, Zhai Q, Lu K, Li H (2017) Suppression of VAMP2 Alters Morphology of the Tegument and Affects Glucose uptake. Dev Reprod Schistosoma Japonicum (March):1-12. https:// doi.org/10.1038/s41598-017-05602-8 
Han Z-G, Brindley PJ, Wang S-Y, Chen Z (2009) Schistosoma genomics: new perspectives on Schistosome biology and host-parasite interaction. Annu Rev Genomics Hum Genet 10(1):211-240. https://doi. org/10.1146/annurev-genom-082908-150036

Hansell E, Braschi S, Medzihradszky KF, Sajid M, Debnath M, Ingram J, Lim KC, McKerrow JH (2008) Proteomic analysis of skin invasion by blood fluke larvae. PLoS Negl Trop Dis 2(7):e262. https://doi. org/10.1371/journal.pntd.0000262

Harrop R, Wilson RA (1993) Protein synthesis and release by cultured schistosomula of Schistosoma mansoni. Parasitology. 107:265-274. https://doi.org/10.1017/s0031182000079245

Hoy AM, Lundie RJ, Ivens A, Quintana JF, Nausch N, Forster T, Jones F, Kabatereine NB, Dunne DW, Mutapi F, MacDonald AS, Buck AH (2014) Parasite-derived MicroRNAs in host serum as novel biomarkers of Helminth infection. PLoS Negl Trop Dis 8(2):e2701. https://doi.org/10.1371/journal.pntd.0002701

Hristov M, Erl W, Linder S, Weber PC (2004) Apoptotic bodies from endothelial cells enhance the number and initiate the differentiation of human endothelial progenitor cells in vitro. Blood 104(9):27612766. https://doi.org/10.1182/blood-2003-10-3614

Hu G, Drescher KM, Chen XM (2012) Exosomal miRNAs: biological properties and therapeutic potential. Front Genet 3. https://doi.org/ 10.3389/fgene.2012.00056

Ingram J, Knudsen G, Lim KC, Hansell E, Sakanari J, McKerrow J (2011) Proteomic analysis of human skin treated with larval schistosome peptidases reveals distinct invasion strategies among species of blood flukes. PLoS Negl Trop Dis 5(9):e1337. https://doi.org/10. 1371/journal.pntd.0001337

Ingram JR, Rafi SB, Eroy-Reveles AA, Ray M, Lambeth L, Hsieh I, Ruelas D, Lim KC, Sakanari J, Craik CS, Jacobson MP, McKerrow JH (2012) Investigation of the proteolytic functions of an expanded cercarial elastase gene family in Schistosoma mansoni. PLoS Negl Trop Dis 6:e1589. https://doi.org/10.1371/journal.pntd. 0001589

Jang-Lee J, Curwen RS, Ashton PD, Tissot B, Mathieson W, Panico M, Dell A, Wilson RA, Haslam SM (2007) Glycomics analysis of Schistosoma mansoni egg and Cercarial secretions. Mol Cell Proteomics 6:1485-1499. https://doi.org/10.1074/mcp.m700004mcp200

Jenkins SJ, Hewitson JP, Jenkins GR, Mountford AP (2005) Modulation of the host's immune response by schistosome larvae. Parasite Immunol 27(10-11):385-393. https://doi.org/10.1111/j.1365-3024. 2005.00789.x

Jílková A, Horn M, Řezáčová P, Marešová L, Fajtová P, Brynda J, Vondrášek J, McKerrow JH, Caffrey CR, Mareš M (2014) Activation route of the Schistosoma mansoni cathepsin B1 drug target: structural map with a glycosaminoglycan switch. Structure 22(12):1786-1798. https://doi.org/10.1016/j.str.2014.09.015

Kaczmarek E, Koziak K, Sévigny J, Siegel JB, Anrather J, Beaudoin AR, Bach FH, Robson SC (1996) Identification and characterization of CD39/vascular ATP diphosphohydrolase. J Biol Chem 271(51): 33116-33122. https://doi.org/10.1074/jbc.271.51.33116

Kanamura HY, Hancock K, Rodrigues V, Damian RT (2002) Schistosoma mansoni heat shock protein 70 elicits an early humoral immune response in S. mansoni infected baboons. Mem Inst Oswaldo Cruz. https://doi.org/10.1590/S007402762002000500022

Knudsen GM, Medzihradszky KF, Lim KC, Hansell E, McKerrow JH (2005) Proteomic analysis of schistosoma mansoni cercarial secretions. Mol Cell Proteomics 4(12):1862-1875. https://doi.org/10. 1074/mcp.M500097-MCP200

Knuhr K, Langhans K, Nyenhuis S, Viertmann K, Overgaard Kildemoes AM, Doenhoff MJ et al (2018) Schistosoma mansoni egg-released IPSE/alpha-1 dampens inflammatory cytokine responses viabasophil interleukin (IL)-4 and IL-13. Front Immunol 9. https:// doi.org/10.3389/fimmu.2018.02293
Koles K, Nunnari J, Korkut C, Barria R, Brewer C, Li Y, Leszyk J, Zhang B, Budnik V (2012) Mechanism of evenness interrupted (Evi)exosome release at synaptic boutons. J Biol Chem 287(20):16820 16834. https://doi.org/10.1074/jbc.M112.342667

Kuchay SM, Chishti AH (2007) Calpain-mediated regulation of platelet signaling pathways. Curr Opin Hematol 14:249-254. https://doi. org/10.1097/MOH.0b013e3280ef68f8

Kuipers ME, Hokke CH, Smits HH, Nolte-"t Hoen ENM (2018) Pathogen-derived extracellular vesicle-associated molecules that affect the host immune system: an overview. Front Microbiol 9(SEP). https://doi.org/10.3389/fmicb.2018.02182

Leontovyč A, Ulrychová L, O’Donoghue AJ, Vondrášek J, Marešová L, Hubálek M, Fajtová P, Chanová M, Jiang Z, Craik CS, Caffrey CR, Mareš M, Dvořák J, Horn M (2018) SmSP2: A serine protease secreted by the blood fluke pathogen Schistosoma mansoni with anti-hemostatic properties. PLoS Negl Trop Dis 12(4):e0006446. https://doi.org/10.1371/journal.pntd.0006446

Li XH, Stark M, Vance GM, Cao JP, Wilson RA (2014) The anterior esophageal region of Schistosoma japonicum is a secretory organ. Parasit Vectors 7:565. https://doi.org/10.1186/s13071-014-0565-8

Li Y, Zheng Q, Bao C, Li S, Guo W, Zhao J, Chen D, Gu J, He X, Huang $\mathrm{S}$ (2015) Circular RNA is enriched and stable in exosomes: a promising biomarker for cancer diagnosis. Cell Res 25:981-984. https:// doi.org/10.1038/cr.2015.82

Liao, Q., Yuan, X., Xiao, H., Liu, C., Lv, Z., Zhao, Y., \& Wu, Z. (2011). Identifying schistosoma japonicum excretory/secretory proteins and their interactions with host immune system. PLoS One, 6(8), 0-10. https://doi.org/10.1371/journal.pone.0023786, e23786

Lin YL, He S (2006) Sm22.6 antigen is an inhibitor to human thrombin. Mol Biochem Parasitol. https://doi.org/10.1016/j.molbiopara.2006. 01.012

Liu F, Cui S-J, Hu W, Feng Z, Wang Z-Q, Han Z-G (2009) Excretory/ secretory proteome of the adult developmental stage of human blood fluke, Schistosoma japonicum. Mol Cell Proteomics. https://doi.org/ 10.1074/mcp.m800538-mcp200

Liu F, Lu J, Hu W, Wang SY, Cui SJ, Chi M, Yan Q, Wang XR, Song HD, Xu XN, Wang JJ, Zhang XL, Zhang X, Wang ZQ, Xue CL, Brindley PJ, McManus DP, Yang PY, Feng Z, Chen Z, Han ZG (2006) New perspectives on host-parasite interplay by comparative transcriptomic and proteomic analyses of Schistosoma japonicum. PLoS Pathog 2:e29. https://doi.org/10.1371/journal.ppat.0020029

Liu J, Zhu L, Wang J, Qiu L, Chen Y, Davis RE, Cheng G (2019) Schistosoma japonicum extracellular vesicle miRNA cargo regulates host macrophage functions facilitating parasitism. PLoS Pathog 15(6):e1007817. https://doi.org/10.1371/journal.ppat. 1007817

Lopes DM, Oliveira SC, Page B, Carvalho LP, Carvalho EM, Cardoso LS (2019) Schistosoma mansoni rSm29 antigen induces a regulatory phenotype on dendritic cells and lymphocytes from patients with cutaneous leishmaniasis. Front Immunol 9. https://doi.org/10.3389/ fimmu.2018.03122

MacGregor AN, Shore SJ (1990) Immunocytochemistry of cytoskeletal proteins in adult Schistosoma mansoni. Int J Parasitol 20(3):279 284. https://doi.org/10.1016/0020-7519(90)90141-9

Madureira PA, Surette AP, Phipps KD, Taboski MAS, Miller VA, Waisman DM (2011) The role of the annexin A2 heterotetramer in vascular fibrinolysis. Blood. 118:4789-4797. https://doi.org/10. 1182/blood-2011-06-334672

Mantel PY, Marti M (2014) The role of extracellular vesicles in Plasmodium and other protozoan parasites. Cell Microbiol 16(3): 344-354. https://doi.org/10.1111/cmi.12259

Marcilla A, Trelis M, Cortés A, Sotillo J, Cantalapiedra F, Minguez MT, Valero ML, Sánchez del Pino MM, Muñoz-Antoli C, Toledo R, Bernal D (2012) Extracellular vesicles from parasitic Helminths contain specific excretory/secretory proteins and are internalized in 
intestinal host cells. PLoS One 7(9):e45974. https://doi.org/10.1371/ journal.pone.0045974

Marques HH, Zouain CS, Torres CBB, Oliveira JS, Alves JB, Goes AM (2008) Protective effect and granuloma down-modulation promoted by RP44 antigen a fructose 1,6 bisphosphate aldolase of Schistosoma mansoni. Immunobiology. 213:437-446. https://doi. org/10.1016/j.imbio.2007.10.002

Mathieson W, Wilson RA (2010) A comparative proteomic study of the undeveloped and developed Schistosoma mansoni egg and its contents: the miracidium, hatch fluid and secretions. Int J Parasitol 40: 617-628. https://doi.org/10.1016/j.ijpara.2009.10.014

McCarthy E, Stack C, Donnelly SM, Doyle S, Mann VH, Brindley PJ, Stewart M, Day TA, Maule AG, Dalton JP (2004) Leucine aminopeptidase of the human blood flukes, Schistosoma mansoni and Schistosoma japonicum. Int J Parasitol 34:703-714. https://doi. org/10.1016/j.ijpara.2004.01.008

Meningher T, Barsheshet Y, Ofir-Birin Y, Gold D, Brant B, Dekel E, Sidi Y, Schwartz E, Regev-Rudzki N, Avni O, Avni D (2020) Schistosomal extracellular vesicle-enclosed miRNAs modulate host T helper cell differentiation. EMBO Rep 21(1):1-17. https://doi.org/ 10.15252/embr.201947882

Meningher T, Lerman G, Regev-Rudzki N, Gold D, Ben-Dov IZ, Sidi Y et al (2017) Schistosomal microRNAs isolated from extracellular vesicles in sera of infected patients: a new tool for diagnosis and follow-up of human schistosomiasis. J Infect Dis 215(3):378-386. https://doi.org/10.1093/infdis/jiw539

Montaner S, Galiano A, Trelis M, Martin-Jaular L, del Portillo HA, Bernal D, Marcilla A (2014) The role of extracellular vesicles in modulating the host immune response during parasitic infections. Front Immunol 5(AUG). https://doi.org/10.3389/fimmu.2014. 00433

Mountford AP, Trottein F (2004) Schistosomes in the skin: a balance between immune priming and regulation. https://doi.org/10.1016/j. pt.2004.03.003

Munder PG, Modolell M, Andreesen R, Weltzien HU, Westphal O (1979) Lysophosphatidylcholine (lysolecithin) and its synthetic analogues. Immunemodulating and other biologic effects. Springer Semin Immunopathol 2:187-203. https://doi.org/10.1007/ bf01891668

Noël F, Cunha VM, Silva CL, Mendonça-Silva DL (2001) Control of calcium homeostasis in Schistosoma mansoni. Mem Inst Oswaldo Cruz 96 Suppl:85-88. https://doi.org/10.1590/s007402762001000900012

Nowacki FC, Swain MT, Klychnikov OI, Niazi U, Ivens A, Quintana JF, Hensbergen PJ, Hokke CH, Buck AH, Hoffmann KF (2015a) Protein and small non-coding RNA-enriched extracellular vesicles are released by the pathogenic blood fluke Schistosoma mansoni. J Extracell Vesicles 4(1):28665. https://doi.org/10.3402/jev.v4.28665

Nowacki FC, Swain MT, Klychnikov OI, Niazi U, Ivens A, Quintana JF et al (2015b) Protein and small non-coding RNA-enriched extracellular vesicles are released by the pathogenic blood fluke Schistosoma mansoni. J Extracell Vesicles 1:1-16

Ornelas AMDM, De Paula RG, Morais ER, Magalhães LG, Silva AMB, Gomes MS, De W (2017) Molecular characterization of transport lectin vesicular integral membrane protein $36 \mathrm{kDa}$ ( VIP36 ) in the life cycle of Schistosoma mansoni:2765-2773. https://doi.org/10. 1007/s00436-017-5587-7

Paveley, R. A., Aynsley, S. A., Cook, P. C., Turner, J. D., \& Mountford, A. P. (2009). Fluorescent imaging of antigen released by a skininvading helminth reveals differential uptake and activation profiles by antigen presenting cells. PLoS Negl Trop Dis, 3(10), 0-3. https:// doi.org/10.1371/journal.pntd.0000528, e528

Piper RC, Katzmann DJ (2007) Biogenesis and function of multivesicular bodies. Annu Rev Cell Dev Biol 23(1):519-547
Ramaswamy K, He Y-X, Salafsky B (1997) ICAM-1 and iNOS expression increased in the skin of mice after vaccination with $\gamma$-irradiated cercariae of schistosoma mansoni. Exp Parasitol 86 (2):118-132

Rao KVN, Ramaswamy K (2000) Cloning and expression of a gene encoding Sm16, an anti-inflammatory protein from Schistosoma mansoni. Mol Biochem Parasitol 108:101-108. https://doi.org/10. 1016/S0166-6851(00)00209-7

Raposo G, Stoorvogel W (2013) Extracellular vesicles: Exosomes, microvesicles, and friends. J Cell Biol 200(4):373-383. https://doi. org/10.1083/jcb.201211138

Rezende CMF, Silva MR, Santos í GD, Silva GAB, Gomes DA, Goes AM (2011) Immunization with $\mathrm{rP} 22$ induces protective immunity against Schistosoma mansoni: effects on granuloma downmodulation and cytokine production. Immunol Lett 141:123-133. https://doi.org/10.1016/j.imlet.2011.09.003

Riveau G, Poulain-Godefroy O, Dupré L, Remoué F, Mielcarek N, Locht C, Capron A (1998) Glutathione S-Transferases of 28kDa as major vaccine candidates against Schistosomiasis. Mem Inst Oswaldo Cruz 93:87-94. https://doi.org/10.1590/S007402761998000700012

Riveau G, Schacht AM, Dompnier JP, Deplanque D, Seck M, Waucquier N, Senghor S, Delcroix-Genete D, Hermann E, Idris-Khodja N, Levy-Marchal C, Capron M, Capron A (2018) Safety and efficacy of the rSh28GST urinary schistosomiasis vaccine: A phase 3 randomized, controlled trial in Senegalese children. PLoS Negl Trop Dis 12(12):1-22. https://doi.org/10.1371/journal.pntd.0006968

Rodriguez-Boulan E, Kreitzer G, Müsch A (2005) Organization of vesicular trafficking in epithelia. Nat Rev Mol Cell Biol 6:233-247. https://doi.org/10.1038/nrm1593

Ruppel A, Chlichlia K, Bahgat M (2004) Invasion by schistosome cercariae: neglected aspects in Schistosoma japonicum. Trends Parasitol 20(9):397-400. https://doi.org/10.1016/j.pt.2004.06.006

Rutitzky LI, Hernandez HJ, Stadecker MJ (2001) Th1-polarizing immunization with egg antigens correlates with severe exacerbation of immunopathology and death in schistosome infection. Proc Natl Acad Sci U S A 98(23):13243-13248. https://doi.org/10.1073/ pnas. 231258498

Salter JP, Lim KC, Hansell E, Hsieh I, McKerrow JH (2000) Schistosome invasion of human skin and degradation of dermal elastin are mediated by a single serine protease. J Biol Chem 275(49):38667-38673. https://doi.org/10.1074/jbc.M006997200

Samoil V, Dagenais M, Ganapathy V, Aldridge J, Glebov A, Jardim A, Ribeiro P (2018) Vesicle-based secretion in schistosomes: analysis of protein and microRNA (miRNA) content of exosome-like vesicles derived from Schistosoma mansoni. Sci Rep 8(1):1-16. https:// doi.org/10.1038/s41598-018-21587-4

Senft AW, Philpott DE, Pelofsky AH (2006) Electron microscope observations of the integument, flame cells, and gut of Schistosoma mansoni. J Parasitol 47:217. https://doi.org/10.2307/3275292

Shimoda M, Khokha R (2013) Proteolytic factors in exosomes. Proteomics. 13:1624-1636. https://doi.org/10.1002/pmic. 201200458

Silva LL, Marcet-Houben M, Nahum LA, Zerlotini A, Gabaldón T, Oliveira G (2012) The Schistosoma mansoni phylome: using evolutionary genomics to gain insight into a parasite's biology. BMC Genomics 13(1):617. https://doi.org/10.1186/1471-2164-13-617

Simpson RJ, Kalra H, Mathivanan S (2012) Exocarta as a resource for exosomal research. J Extracell Vesicles 1. https://doi.org/10.3402/ jev.v1i0.18374

Skelly PJ, Da'dara AA, Li XH, Castro-Borges W, Wilson RA (2014) Schistosome feeding and regurgitation. PLoS Pathog 10(8): e1004246. https://doi.org/10.1371/journal.ppat.1004246

Sotillo J, Pearson M, Potriquet J, Becker L, Pickering D, Mulvenna J, Loukas A (2016a) Extracellular vesicles secreted by Schistosoma mansoni contain protein vaccine candidates. Int J Parasitol 46(1):15. https://doi.org/10.1016/j.jpara.2015.09.002 
Sotillo J, Pearson M, Potriquet J, Becker L, Pickering D, Mulvenna J, Loukas A (2016b) Extracellular vesicles secreted by Schistosoma mansoni contain protein vaccine candidates. Int J Parasitol 46(1):15. https://doi.org/10.1016/j.ijpara.2015.09.002

Stroehlein AJ, Young ND, Korhonen PK, Hall RS, Jex AR, Webster BL, Rollinson D, Brindley PJ, Gasser RB (2018) The small RNA complement of adult Schistosoma haematobium. PLoS Negl Trop Dis 12(5):1-15. https://doi.org/10.1371/journal.pntd.0006535

Sun W, Liu S, Brindley PJ, McManus DP (1999) Bacterial expression and characterization of functional recombinant triosephosphate isomerase from Schistosoma japonicum. Protein Expr Purif 17: 410-413. https://doi.org/10.1006/prep.1999.1140

Taylor MD, van der Werf N, Maizels RM (2012) T cells in helminth infection: the regulators and the regulated. Trends Immunol 33(4): 181-189. https://doi.org/10.1016/j.it.2012.01.001

Torgerson PR, Devleesschauwer B, Praet N, Speybroeck N, Willingham AL, Kasuga F, Rokni MB, Zhou XN, Fèvre EM, Sripa B, Gargouri N, Fürst T, Budke CM, Carabin H, Kirk MD, Angulo FJ, Havelaar A, de Silva N (2015) World Health Organization estimates of the global and regional disease burden of 11 foodborne parasitic diseases, 2010: A data synthesis. PLoS Med 12(12):1-22. https://doi. org/10.1371/journal.pmed.1001920

Tran MH, Freitas TC, Cooper L, Gaze S, Gatton ML, Jones MK, Lovas E, Pearce EJ, Loukas A (2010) Suppression of mRNAs encoding tegument Tetraspanins from Schistosoma mansoni results in impaired tegument turnover. PLoS Pathog 6:e1000840. https://doi. org/10.1371/journal.ppat.1000840

Tran MH, Pearson MS, Bethony JM, Smyth DJ, Jones MK, Duke M, Don TA, McManus DP, Correa-Oliveira R, Loukas A (2006) Tetraspanins on the surface of Schistosoma mansoni are protective antigens against schistosomiasis. Nat Med 12:835-840. https://doi. org/10.1038/nm1430

Turchinovich A, Samatov TR, Tonevitsky AG, Burwinkel B (2013) Circulating miRNAs: cell-cell communication function? Front Genet 4. https://doi.org/10.3389/fgene.2013.00119

Van der Kleij D, Latz E, Brouwers JFHM, Kruize YCM, Schmitz M, Kurt-Jones EA et al (2002) A novel host-parasite lipid cross-talk. Schistosomal lyso-phosphatidylserine activates toll-like receptor 2 and affects immune polarization. J Biol Chem 277(50):4812248129. https://doi.org/10.1074/jbc.M206941200

van Dongen HM, Masoumi N, Witwer KW, Pegtel DM (2016) Extracellular vesicles exploit viral entry routes for cargo delivery.
Microbiol Mol Biol Rev 80(2):369-386. https://doi.org/10.1128/ mmbr.00063-15

Vasconcelos EG, Ferreira ST, De Carvalho TMU, De Souza W, Kettlun AM, Mancilla M et al (1996) Partial purification and immunohistochemical localization of ATP diphosphohydrolase from Schistosoma mansoni: immunological cross-reactivities with potato apyrase and toxoplasma gondii nucleoside triphosphate hydrolase. J Biol Chem 271(36):22139-22145. https://doi.org/10.1074/jbc.271. 36.22139

Wang J, Zhao F, Yu CX, Xiao D, Song LJ, Yin XR, Shen S, Hua WQ, Zhang JZ, Zhang HF, He LH, Qian CY, Zhang W, Xu YL, Yang J (2013) Identification of proteins inducing short-lived antibody responses from excreted/secretory products of Schistosoma japonicum adult worms by immunoproteomic analysis. J Proteome 87:53-67. https://doi.org/10.1016/j.jprot.2013.05.003

Wang L, Li Z, Shen J, Liu Z, Liang J, Wu X, Sun X, Wu Z (2015) Exosome-like vesicles derived by Schistosoma japonicum adult worms mediates M1 type immune- activity of macrophage. Parasitol Res 114:1865-1873. https://doi.org/10.1007/s00436-0154373-7

Wang Q, Da'dara AA, Skelly PJ (2017) The human blood parasite Schistosoma mansoni expresses extracellular tegumental calpains that cleave the blood clotting protein fibronectin. Sci Rep 7(1): 12912. https://doi.org/10.1038/s41598-017-13141-5

Zhang C, He X, Fan X, Lei N, Sun Y, Zheng K et al (2017) MicroRNA351 promotes schistosomiasis-induced hepatic fibrosis by targeting the vitamin D receptor. Proc Natl Acad Sci 115(1):180-185. https:// doi.org/10.1073/pnas.1715965115

Zhang M, Hong Y, Han Y, Han H, Peng J, Qiu C, Yang J, Lu K, Fu Z, Lin J (2013) Proteomic analysis of tegument-exposed proteins of female and male Schistosoma japonicum worms. J Proteome Res 12(11):5260-5270. https://doi.org/10.1021/pr400476a

Zhu S, Wang S, Lin Y, Jiang P, Cui X, Wang X, Zhang Y, Pan W (2016) Release of extracellular vesicles containing small RNAs from the eggs of Schistosoma japonicum. Parasit Vectors 9(1):1-9. https:// doi.org/10.1186/s13071-016-1845-2

Publisher's note Springer Nature remains neutral with regard to jurisdictional claims in published maps and institutional affiliations. 